15 McKenzie PJ, Wishart HY, Smith G. Longterm outcome after repair of fractured neck of femur. Comparison of subarachnoid and general anaesthesia. Br J Anaesth 1984; 56: 581-6.

\section{The use of partial antagonist analgesics in the treatment of acute and chronic pain}

Keith Budd MB CH B FFARCS, Department of Anaesthesia, Bradford Royal Infirmary, Bradford, England.

The synthesis of $\mathrm{N}$-allylnormorphine (nalorphine) from morphine in $1942^{1}$ was rapidly followed by descriptions of its antagonist action towards morphine. ${ }^{2,3}$ Not until 1954, however, was the analgesic activity of nalorphine described. ${ }^{4}$ Subsequent work prompted Martin to propose his "receptordualism" theory of opiate receptors in the light of a comparison of clinical effects of nalorphine and morphine. ${ }^{5}$ Although nalorphine had analgesic properties, the psychotomimetic side effects rendered it unacceptable as a clinically useful drug. However, a series of acceptable agents with both analgesic and morphine-antagonistic properties have since been introduced and have become known as a partial agonist or agonist-antagonist analgesics.

In terms of receptor activity, the various opiate agents may thus be differentiated, as summarized in Table I.

Following Martin's original proposal of the concept of receptor dualism, much evidence has accumulated in support of the heterogeneous nature of the opiate receptor population. Continuing work has led to the description of several receptors, including mu and kappa (mediating analgesia), and sigma (mediating dysphoria), with analgesic agents of both agonist and partial agonist type having valuable effects at each receptor site. ${ }^{6}$ Consequent$\mathrm{ly}$, the partial agonist analgesics may be subdivided by their receptor activity and side effect profiles.

Nalorphine-like: e.g., pentazocine, butorphanol, nalbuphine

- these are mu antagonists and kappa, sigma agonists.

Morphine-like: e.g., buprenorphine, profadol, propiram

- these are mu agonists; kappa antagonists; no apparent sigma effect.

While having many of the properties of the pure agonist, the partial agonists exhibit two which are essentially different. They have extremely low liability to produce physical and psychological dependence and their log dose-response curves for all clinical properties show a pronounced ceiling effect. This latter property potentially limits clinical value, particularly as analgesics. This ceiling effect has not been obtained, however, with the mu agonist buprenorphine where the log dose-response curve is similar to that of the pure agonist when analgesia is the measured response. The clinical usefulness of the partial agonists may be divided into two main areas (Table II).

TABLE I Differentiation of opiate agents by receptor affinity and intrinsic activity

\begin{tabular}{lll}
\hline Agent & Receptor affinity & Intrinsic activity \\
\hline $\begin{array}{lll}\text { Agonist } \\
\text { e.g., morphine }\end{array}$ & ++ & ++ \\
$\begin{array}{l}\text { Partial agonist } \\
\text { e.g., pentazocine }\end{array}$ & ++ & +- \\
$\begin{array}{l}\text { Antagonist } \\
\text { e.g., naloxone }\end{array}$ & ++ & - \\
\hline
\end{tabular}

TABLE II Clinical usefulness of the partial agonists

kappa agonists

e.g., pentazocine, butorphanol, nalbuphine

- limited analgesic efficacy

- duration of effect 4 hours given orally or intravenously

- side effects: hypnosis, emesis, dysphoria, respiratory depression

mu agonists

e.g., buprenophine

- analgesic efficacy similar to agonists

- potency 30 times that of morphine

- curation of effect 6-24 hours (dose dependent)

- side effects: emesis, dizziness, minimal hypnosis, respiratory depression 
In 1983 meptzinol was also introduced into clinical practice in the United Kingdom. This is a novel compound with analgesic potency and side effects similar to those of the kappa agonists. However, certain differences, both clinical and biochemical, become apparent with this agent. Cardiovascular and respiratory depression were not observed and the mode of action appeared to be via a central cholinergic mechanism which was unique amongst postulated modes of action of analgesic agents. $^{8}$

The majority of the partial agonist group of analgesics have been available in parenteral and oral formulation. However, buprenorphine, because of a significant (90 per cent) first pass elimination in the gut wall, is available as a sublingual formulation providing an early onset of action (510 minutes). Buprenorphine also appears to have certain advantages over other partial agonists with a significantly prolonged duration of action $(8-16$ hours) when given by any route. Its dose-response curve for respiratory depression shows a unique profile in that it is bell-shaped with a peak at about $1 \mathrm{mg}$. Increasing the dose thereafter reduces the depressant effect and as blood concentrations decay, no reversion to a state of respiratory depression is seen. Significantly, no respiratory depression has been described with the sublingual formulation at any dose, or in combination with any other agents. ${ }^{9}$

In comparison with pure agonists, the partial agonists have the major advantage of low dependence liability. Their duration of action and side effect profile is otherwise comparable with that of the pure agonists, apart from buprenorphine which has a significantly longer duration of activity than the remainder. ${ }^{10}$

When used in the epidural or intrathecal spaces, receptor binding and lipophilicity play an important part in the degree and duration of analgesia as well as the side effects seen. High lipophilicity will ensure adequate penetration to the cord receptors and prolonged receptor occupancy will ensure sustained duration of the effect up to 48 hours. Administered epidurally, the kappa agonists appear to have a relatively short (four to eight hours) duration of effect and the activity of the mu agonist, buprenorphine, is particularly variable. However, administered intrathecally, the high lipophilicity and long duration of receptor binding of buprenor- phine make it the ideal agent because of a low incidence of side effects but a high degree of analgesia of long duration.

Although Ariens et al. ${ }^{11}$ postulated on theoretical grounds that the administration of agonist and partial agonist together or sequentially would result in antagonism and reduced analgesia, more recent clinical work has failed to substantiate this. It would appear that pure agonist and kappa partial agonist do not oppose each other's analgesic effect and that pure agonist and mu partial agonist may well summate in their analgesic activity.*

In general, the partial agonists, especially buprenorphine with its potency and long duration of action, have a significant clinical value because of their low dependence liability. Whether further development in this series of compounds will produce agents nearer to the ideal is yet to be determined. Perhaps the ideal analgesic will need to be sought in areas far removed both chemically and pharmacologically from opium derivatives.

\section{References}

1 Weijlard J, Erickson AE. N-allylnormorphine. J Am Chem Soc 1942; 64: 869-70.

2 Unnal $K$. Antagonistic effects of $\mathrm{N}$-allylnormorphine upon morphine. J Pharmacol Exp Ther 1943; 79: 27-31.

3 Hart ER, McCawley EL The pharmacology of $\mathrm{N}$-allylnormorphine as compared to morphine. J Pharmacol Exp Ther 1944; 82: 339-48.

4 Lasagna $L$, Beecher $H K$. The analgesic effectiveness of nalorphine and nalorphine-morphine combinations in man. J Pharmacol Exp Ther 1954; 122: 356-63.

5 Martin WR. Opioid antagonists. Pharmacol Rev 1967; 10: 463-521.

6 Simon EJ, Hiller JM. Multiple Opioid Receptors: in "Opioids: Past, Present \& Future." Ed Hughes J, Collier H, Rance MJ, Tyers MB. London, Taylor \& Francis, 1984.

7 Rance MJ. Multiple opiate receptors - their occurrence and significance. Clinics in Anesthesiology 1983; 1 : 183-99.

${ }^{*} B u d d K$. Clinical interaction of agonist and partial agonist opiate analgesics. Paper delivered at 4 th World Congress on Pain, Seattle, 1984. 
8 Budd K, Brown PM, Robson PJ. In treatment of chronic pain by use of Meptazinol administered into the epidural space. Postgrad Med J 1983; 595: 68-71.

9 Budd K. Buprenophine. Clinics in Anesthesiology 1983; $1: 147-52$.

10 Houde $R W$. Analgesic effectiveness of the narcotic agonist-antagonists. Br J Clin Pharm 1979; 7 : 2795 3085.

11 Ariens EJ, Simonis AM, Van Rossum JM. "Molecular pharmacology: The Mode of Action of Biologically Active Compounds." New York, Academic Press 1964. 